\title{
Histologic review of melanomas by pathologists trained in melanocytic lesions may change therapeutic approach in up to $41.9 \%$ of cases*
}

\author{
Nathalie Mie Suzuki ${ }^{1}$, Maria Isabel Ramos Saraiva ${ }^{1,2}$, Gabriela Cunha Capareli ${ }^{1}$ \\ Luiz Guilherme Martins Castro ${ }^{1,2}$
}

DOI: http://dx.doi.org/10.1590/abd1806-4841.20187209

\begin{abstract}
Melanoma Guidelines of the Brazilian Dermatology Society recommend histologic review by pathologists trained in melanocytic lesions whenever possible. Out of 145 melanoma cases identified at a private clinic in São Paulo/Brazil, 31 that had been submited to histologic review were studied to evaluate whether revision had led to change in therapeutic approach.. Differences in original/reviewed reports were found in $58.1 \%(n=18)$ of the reports, leading to changes in therapeutic approach in $41.9 \%(n=13)$. Change in diagnosis was observed in 6 out of $31(19,3 \%)$ cases. These findings suggest that second opinion by pathologists trained in melanocytic lesions is likely to show significant differences from the original report.
\end{abstract}

Keywords: Diagnosis; Histology; Melanoma

Histology is the gold standard for diagnosis of melanoma. It determines prognosis and therapeutic approach but is susceptible to interpretation bias by the pathologist/dermatopathologist (P/DP).

In order to standardize histologic reports in melanoma and to decrease bias, the International Collaboration on Cancer Reporting (ICCR) suggests the following mandatory elements for inclusion in these reports: involvement and distance of margins, presence or absence of dermal invasion, Breslow index for invasive cases, mitotic index, presence or absence of ulceration, and presence or absence of microsatellitosis. ${ }^{1}$

The latest guidelines on melanoma of the Brazilian Dermatology Society (SBD) recommend histologic review by a P/DP experienced in melanocytic lesions whenever possible before indicating treatment. $^{2}$
This study's objective was to assess whether histologic review of melanoma cases performed by a P/DP experienced in melanocytic lesions leads to changes in therapeutic approach.

A retrospective study was conducted in a private clinic in São Paulo, Brazil, covering a 25-year span (1991-2016).

The clinic works routinely with three pathology laboratories that are known for their expertise in dermatologic oncology and melanocytic lesions. Reports from other laboratories were reviewed whenever the result specified melanoma or when a melanocytic lesion could not be classified clearly as benign, premalignant, or malignant.

There were 145 diagnoses of melanoma during the period, of which $21.4 \%(n=31)$ were submitted to review by an expert pa-

\footnotetext{
Received 15 April 2017.

Accepted 31 October 2017.

* Work performed at Oncoderma, São Paulo (SP), Brazil.

Financial support: None.

Conflict of interest: None.

Oncoderma, São Paulo (SP), Brazil.

Center for Cutaneous Oncology, Hospital Alemão Oswaldo Cruz, São Paulo (SP), Brazil.
}

MAILING ADDRESS:

Nathalie Mie Suzuki

E-mail: nathalie.suzuki@gmail.com 
thologist in melanocytic lesions. The original and revised reports were compared as to TNM classification, diagnosis, and implications for treatment approach.

After histologic review there was no change in TNM classification in $13(41.9 \%)$ cases, nor was treatment approach altered.

Differences in histologic reports were observed in $58.1 \%$ (n $=18$ ) of the reviewed cases. TNM classification changed in 38.7\% (n $=12$ ) of the cases. Of these, the main differences in reports leading to to changes in TNM classification referred to: Breslow index in $91.7 \%$ $(\mathrm{n}=11)$; mitotic index in 58.3\% $(\mathrm{n}=7)$; and Clark level in $33.3 \%(\mathrm{n}$ =4) (Table 1).

Diagnostic discordance occurred in 19.3\% $(n=6)$ of the cases. Four cases with initial diagnosis of dysplastic nevus had diagnosis revised to in situ melanoma (upstaging), and two cases initially diagnosed as in situ melanoma had diagnosis revised to junctional nevi (downstaging) (Table 1 and Figure $1 \mathrm{~A})$.

Histologic review led to change in treatment approach in $41.9 \%$ of cases $(n=13)$. Changes consisted of indication versus non-indication of sentinel lymph node biopsy (SLN) and modification urgical margin size. In more than half of the cases in which there was a change in treatment approach $(53.8 \% ; n=7)$, the new approach was less invasive (Figure 1B).
Performed at findings from this study in a private clinic specialized in dermatologic oncology in São Paulo is in accordance with those of other studies in dermatologic oncology centers around the world.

Present literature shows that histologic review can lead to change in diagnosis in nearly one-fifth of cases; in the current study, diagnosis was changed in $19.3 \%$ of cases, a proportion within the range from $2.9 \%$ to $27 \%$ reported in previous studies. ${ }^{3-10}$

Among cases where melanoma diagnosis was confirmed by revision, TNM classification changed in $38.7 \%$. Although change in histologic staging is frequently seen in literature, rates are lower than those observed in the present study. In studies performed in cancer referral centers in the United States and Australia, the proportion of staging change varied from $22.1 \%$ to $24 \%{ }^{3,4}$ In these two referral centers, it is common practice to order histologic review of all incoming referrals before initiating treatment.

Our findings may have a bias due to the lack of specific criteria for selecting cases for review. Future studies might also consider joint review by pathologists who evaluated the case (first histology and review) in order to reach an agreement, or even a review by two P/DPs in order to increase diagnostic accuracy.

TABLE 1: Comparison of histologic characteristics of 18 reviewed melanoma cases that changed the diagnosis/TNM classification

TARGET HISTOLOGIC CHARACTERISTICS

VARIATION IN TNM

CLASSIFICATION

\begin{tabular}{|c|c|c|c|c|c|c|c|c|}
\hline \multirow[b]{2}{*}{ CASES } & \multicolumn{2}{|c|}{$\begin{array}{l}\text { BRESLOW INDEX } \\
\text { (in } \mathrm{mm} \text { ) }\end{array}$} & \multicolumn{2}{|c|}{$\begin{array}{l}\text { MITOTIC INDEX } \\
\text { (mitoses per } 10 \text { fields) }\end{array}$} & \multicolumn{2}{|c|}{ CLARK LEVEL } & \multirow[b]{2}{*}{ 1st REPORT } & \multirow[b]{2}{*}{ REVIEW } \\
\hline & 1st REPORT & REVIEW & 1st REPORT & REVIEW & 1st REPORT & REVIEW & & \\
\hline $1^{*}$ & 0.4 & 0.21 & 1 & 0 & II & II & T1bN0M0 & T1aN0M0 \\
\hline $2^{*}$ & 1 & 1.2 & 3 & 2 & III & III & T1bN0M0 & T2aN0M0 \\
\hline $3^{* *}$ & 0.2 & 0.4 & 0 & 1 & II & II & T1aN0M0 & T1bN0M0 \\
\hline $4^{*}$ & 3 & 0.9 & 1 & 0 & III & IV & T3aN0M0 & T1aN0M0 \\
\hline $5^{*}$ & 0.55 & 0.55 & 1 & 0 & II & II & T1bN0M0 & T1aN0M0 \\
\hline $6^{* *}$ & in situ & 0.2 & in situ & 0 & in situ & III & TisN0M0 & T1aN0M0 \\
\hline $7^{* *}$ & $\mathrm{NC}$ & 1.4 & 2 & 2 & $\mathrm{NC}$ & NC & TxNOM0 & T2bN0M0 \\
\hline $8^{*}$ & 1.5 & 0.3 & 0 & 0 & III & II & T2aN0M0 & T1aN0M0 \\
\hline $9^{* *}$ & 0.88 & 1.05 & 0 & 0 & III & II & T1aN0M0 & T2aN0M0 \\
\hline $10^{*}$ & 2.14 & 1 & 0 & 0 & II & II & T3aN0M0 & T1aN0M0 \\
\hline $11^{*}$ & 1.8 & 2.2 & 8 & 17 & III & IV & T2bN0M0 & T3aN0M0 \\
\hline $12^{*}$ & 0.4 & 0.5 & 1 & 0 & II & II & T1bN0M0 & T1aN0M0 \\
\hline $13^{* *}$ & $\mathrm{NC}$ & in situ & NC & in situ & $\mathrm{NC}$ & in situ & TONOM0 & TisN0M0 \\
\hline $14^{* *}$ & NC & 0.7 & NC & 0 & NC & II & TONOM0 & T1aN0M0 \\
\hline $15^{* *}$ & NC & 5.58 & NC & 4 & NC & V & TONOM0 & T4aN0M0 \\
\hline $16^{* *}$ & $\mathrm{NC}$ & in situ & $\mathrm{NC}$ & in situ & NC & in situ & TONOM0 & TisN0M0 \\
\hline $17^{*}$ & in situ & NC & in situ & NC & in situ & NC & TisN0M0 & TONOM0 \\
\hline $18^{*}$ & in situ & NC & in situ & $\mathrm{NC}$ & in situ & $\mathrm{NC}$ & TisN0M0 & TONOMO \\
\hline
\end{tabular}

* $=$ downstaging; ${ }^{* *}=$ upstaging; $\mathrm{NC}=$ not classifiable 


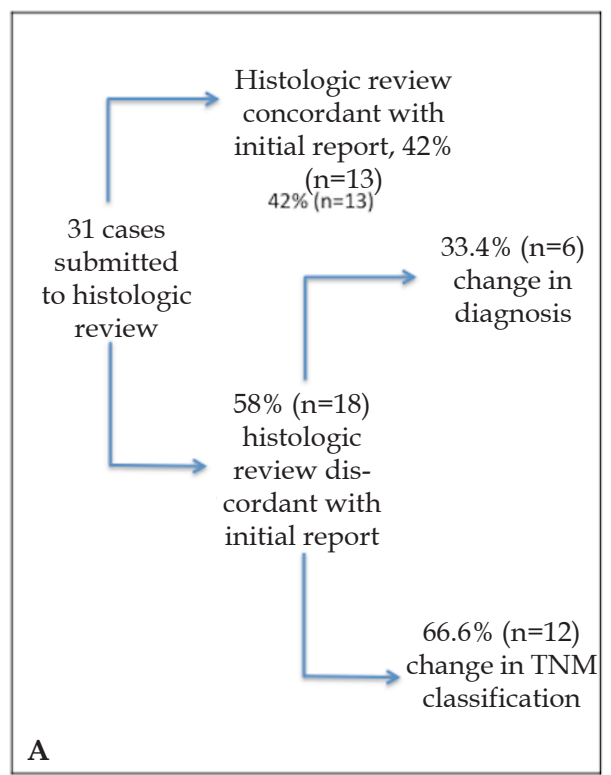

FiguRE 1: A - Concordance between initial /review reports of 31 melanoma cases and change in diagnosis/TNM classification; B - evaluation of change in treatment approach in melanoma cases submitted to histologic review
The main changes in treatment approach, corroborating other studies, were change in the size of surgical margins and indication or not of SLN biopsy (dictated manly by changes in the mitotic index or Breslow thickness). ${ }^{3,4}$

One unique finding in this study was that the majority of therapeutic changes resulting from the reviews led to less invasive, approach, a finding not reported previously in literature.
Based on the current findings, we conclude that the review of histologic examination in melanoma by a P/DP experienced in melanocytic lesions altered the treatment approach in $41.9 \%$, making it less invasive in the majority of these cases.

Our study supports the recommendation in the SBD guidelines in favor of a second opinion by an expert pathologist in melanoma cases. $\square$

\section{REFERENCES}

1. Scolyer RA, Judge MJ, Evans A, Frishberg DP, Prieto VG, Thompson JF, et al. International Collaboration on Cancer Reporting. Dataset for pathology reporting of cutaneous invasive melanoma: recommendations from the international collaboration on cancer reporting (ICCR). Am J Surg Pathol. 2013;37:1797-814.

2. Castro LG, Messina MC, Loureiro W, Macarenco RS, Duprat Neto JP, Di Giacomo $\mathrm{TH}$, et al. Guidelines of the Brazilian Dermatology Society for diagnosis, treatment and follow up of primary cutaneous melanoma. Part I. An Bras Dermatol. 2015;90:851-61.

3. Santillan AA, Messina JL, Marzban SS, Crespo G, Sondak VK, Zager JS. Pathology review of thin melanoma and melanoma in situ in a multidisciplinary melanoma clinic: impact on treatment decisions. J Clin Oncol. 2010;28:481-6.

4. Niebling MG, Haydu LE, Karim RZ, Thompson JF, Scolyer RA. Pathology review significantly affects diagnosis and treatment of melanoma patients: an analysis of 5011 patients treated at a melanoma treatment center. Ann Surg Oncol. 2014;21:2245-51.

5. Shoo BA, Sagebiel RW, Kashani-Sabet M. Discordance in the histopathologic diagnosis of melanoma at a melanoma referral center. J Am Acad Dermatol. 2010;62:751-6.

6. van Dijk MC, Aben KK, van Hees F, Klaasen A, Blokx WA, Kiemeney LA, et al Expert review remains important in the histopathological diagnosis of cutaneous melanocytic lesions. Histopathology. 2008;52:139-46.

7. McGinnis KS, Lessin SR, Elder DE, Guerry D 4th, Schuchter L, Ming M, et al. Pathology review of cases presenting to a multidisciplinary pigmented lesion clinic. Arch Dermatol. 2002;138:617-21.

8. Brochez L, Verhaeghe E, Grosshans E, Haneke E, Piérard G, Ruiter D, et al. Interobserver variation in the histopathological diagnosis of clinically suspicious pigmented skin lesions. J Pathol. 2002;196:459-66.

9. Farmer ER, Gonin R, Hanna MP. Discordance in the histopathologic diagnosis of melanoma and melanocytic nevi between expert pathologists. Hum Pathol. 1996;27:528-31.

10. Kronz JD, Westra WH, Epstein Jl. Mandatory second opinion surgical pathology at a large referral hospital. Cancer. 1999;86:2426-35.

AUTHORS'CONTRIBUTIONS
Nathalie Mie Suzuki
Statistical analysis, Approval of the final version of the manuscript, Design and plan-
ning of the study, Preparation and writing of the manuscript, Collecting, analysis and
interpretation of data, Critical review of the literature, Critical review of the manuscript
Maria Isabel Ramos Saraiva
Approval of the final version of the manuscript, Design and planning of the study, Prepa-
ration and writing of the manuscript, Collecting, analysis and interpretation of data,
Critical review of the manuscript

\begin{abstract}
Gabriela Cunha Capareli ORCID 0000-0001-6775-2424

Preparation and writing of the manuscript, Critical review of the manuscript Luiz Guilherme Martins Castro $\quad$ (iD) ORCID 0000-0002-6269-1957

Approval of the final version of the manuscript, Design and planning of the study, Preparation and writing of the manuscript, Effective participation in research orientation, Intellectual participation in propaedeutic and/or therapeutic conduct of studied cases, Critical review of the manuscript
\end{abstract}

How to cite this article: Suzuki NM, Saraiva MIR, Capareli GC, Castro LGM. Histologic review of melanomas by pathologists trained in melanocytic lesions may change therapeutic approach in up to 41.9\% of cases. An Bras Dermatol. 2018;93(5):752-4. 